\title{
The Vaccine Coverage and Vaccine Immunity Status and Risk Factors of Non-Protective Levels of Antibodies Against Vaccines in Children with Juvenile Idiopathic Arthritis: Russian Tertiary Centre Study.
}

\section{Mikhail Kostik ( $\sim$ kost-mikhail@yandex.ru )}

Sankt-Peterburgskij gosudarstvennyj pediatriceskij medicinskij universitet https://orcid.org/0000-0002-1180-8086

\section{Natalia A. Lubimova}

FGBU NMIC im V A Almazova: FGBU Nacional'nyj medicinskij issledovatel'skij centr imeni V A Almazova

Irina V. Fridman

Naučno-issledovatel'skij institut detskih infekcij Federal'nogo mediko-biologiceskogo agentstva Rossii: FGBU Detskij naucnokliniceskij centr infekcionnyh boleznej Federal'nogo mediko-biologiceskogo agentstva Rossii

\section{Olga V. Goleva}

Naučno-issledovatel'skij institut detskih infekcij Federal'nogo mediko-biologiceskogo agentstva Rossii: FGBU Detskij naucnokliniceskij centr infekcionnyh boleznej Federal'nogo mediko-biologiceskogo agentstva Rossii

\section{Susanna M. Kharit}

Naučno-issledovatel'skij institut detskih infekcij Federal'nogo mediko-biologiceskogo agentstva Rossii: FGBU Detskij naucnokliniceskij centr infekcionnyh boleznej Federal'nogo mediko-biologiceskogo agentstva Rossii

\section{Research article}

Keywords: juvenile idiopathic arthritis, measles, mumps, rubella, diphtheria, hepatitis B, vaccines, protective level of antibodies against vaccines

Posted Date: January 18th, 2021

DOI: https://doi.org/10.21203/rs.3.rs-147668/v1

License: (c) (1) This work is licensed under a Creative Commons Attribution 4.0 International License. Read Full License

Version of Record: A version of this preprint was published at Pediatric Rheumatology on July 5th, 2021. See the published version at https://doi.org/10.1186/s12969-021-00594-2. 


\section{Abstract}

Background: Immunosuppressive drugs, decreased vaccine coverage, aberrant immunity might be factors of low anti-vaccine antibodies in JIA patients. The study aimed to evaluate vaccine coverage, post-vaccine immunity and risk factors of nonprotective levels of antibodies against measles, mumps, rubella, hepatitis B and diphtheria in JIA patients.

Methods: A prospective study included 170 children diagnosed with JIA aged 2 to 17 years, who received routine vaccinations against measles, rubella, mumps (MMR) diphtheria and hepatitis B. In all patients, the levels of post-vaccination antibodies (IgG) for measles, rubella, mumps, hepatitis B and diphtheria measured with ELISA.

Results: Protective level of antibodies were 50\% against hepatitis B, 52\% - diphtheria, $58 \%$ - measles, $80 \%$ - mumps, $98 \%$ rubella. The best coverage for MMR had patients with enthesytis-related arthritis-85\%, compare to oligoarthritis-70\%, polyarthritis-69\%, systemic arthritis-63\%. Diphtheria coverage was 50\%, 51\%, 46\%, 63\%, respectively. Incomplete MMR vaccination had $39 \%$ patients, treated with biologics, $22 \%$ with methotrexate and $14 \%$ with NSAID ( $p=0.025)$, and $61 \%, 46 \%$, $36 \%$ for diphtheria $(p=0.021)$. Incomplete vaccination was a risk factor of non-protective level of antibodies against measles ( $\mathrm{HR}=2.03$ [95\%Cl: 1.02; 4.0], $\mathrm{p}=0.042)$, parotitis ( $\mathrm{HR}=6.25$ [95\%Cl: 2.13; 17.9], $\mathrm{p}=0.0008)$ and diphtheria (HR=2.39 [95\%Cl: 1.18; 4.85], $\mathrm{p}=0.016$ ) vaccines, as well as JIA category, biologics, corticosteroids and long-term methotrexate treatment for distinct vaccines.

Conclusion: Children with JIA may have lower anti-vaccine antibodies levels and required routine check, especially in children with incomplete vaccination, biologics, systemic arthritis and long-term methotrexate treatment.

\section{Key Messages}

1. Children with JIA have decreased protective level of antibodies against vaccines.

2. Vaccine coverage in JIA children is lower than in healthy peers.

3. Incomplete vaccination, biologics, JIA category and long term methotrexate treatment are the main factors of nonprotective levels of antibodies against vaccines.

\section{Introduction}

Juvenile idiopathic arthritis (JIA) is the most common pediatric rheumatic disease (PRD) with a prevalence of between 16 and 150 per 100,000 children [1]. Both innate and adaptive immune systems are associated with several other factors, contributing to the pathological development of chronic inflammation in patients with JIA [2]. The main goal of the JIA treatment is control of immune-mediated inflammation with different medication, e.g. corticosteroids, methotrexate and biologics [1]. Patients with JIA are at greater risk of infections than healthy children due to their aberrant immunity and using immunosuppressive drugs [3]. They might have more infections required hospital admissions (e.g. pneumonia or sepsis) [4]. Biologic agents, especially TNF-a inhibitors, change the structure of infection diseases in JIA patients [5-7]. The infection episodes are the main reason for missing the biologic and methotrexate with subsequent JIA flares, impaired JIA remission and outcomes [8, 9]. Vaccinations can decrease the number of infection episodes and maintain treatment of the disease and hold remission [10]. Escalation of treatment regimens might alter "protective" immune response (e.g., suppression of T and B cells and impaired antibody production) and increases the risk of infections [11, 12]. Many children with PRD stop vaccinating when a diagnosis of rheumatic disease is established [13]. Many practising pediatricians and pediatric rheumatologists continue to believe that the immune response of JIA patients disrupted by immunosuppressive drugs and does not lead to the proper level of seroprotection $[14,15]$. Some physicians fear that vaccines may cause a persistent autoimmune response, lead to severe disease, or relapse to existing diseases $[14,15]$. The fear of parents before the risk of a flare of rheumatic disease due to vaccination leads to the omitting vaccinations, usually recommended by the health authorities for healthy children [13]. Children who have younger-onset age of JIA are in the risk of incomplete vaccination and often miss revaccination against 
measles, rubella, mumps and diphtheria [16]. As a result, we have a rather large cohort of immune-compromised children with incomplete vaccination.

\section{Methods}

To evaluate vaccine coverage, post-vaccine immunity and risk factors of non-protective levels of antibodies against measles, mumps, rubella, hepatitis B and diphtheria in JIA patients, we have performed our study.

A prospective pilot study included data from 170 children diagnosed with juvenile idiopathic arthritis - JIA (55 boys and 115 girls) aged 2 to 17 years, who received routine vaccinations against measles, rubella, mumps (MMR) and diphtheria. The diagnosis of JIA based on the ILAR criteria (1997) [17].

In all patients, the levels of post-vaccination antibodies ( $\mathrm{lgG}$ ) for measles, rubella, mumps, hepatitis B and diphtheria measured with ELISA. IgG concentrations determined from calibration curves constructed using Dynex Technologies Inc. software (USA). The protective level of antibodies was established in accordance with the criteria specified in the manufacturer's instructions: for measles lgG $-0.18 \mathrm{IU} / \mathrm{ml}$ (coefficient of variation, CV, $8 \%$; analytical sensitivity $0.07 \mathrm{IU} / \mathrm{ml}$ ), for antibodies to rubella - $10 \mathrm{IU} / \mathrm{ml}(8 \% ; 2 \mathrm{IU} / \mathrm{ml})$, for hepatitis B (anti-HBs antibodies) - $10 \mathrm{mME} / \mathrm{ml}$ (8\%; $2 \mathrm{mlU} / \mathrm{ml}$ ), for diphtheria $-0.09 \mathrm{IU} / \mathrm{ml}(7,5 \% ; 0.004 \mathrm{lU} / \mathrm{ml})$. The minimal protective level of $\mathrm{IgG}$ against mumps established with a positivity coefficient $>$ 1.0. To detect measles, rubella, mumps and hepatitis $B$ antibodies, we used the commercial kit, created by VectorBest JSC, Russia and IBL International GMBH (Germany) for diphtheria antibodies. Information about the scheduled vaccination against MMR, hepatitis $B$ and diphtheria, JIA course and treatment obtained from the patient's charts. The following classes of immunosuppressive medications, which were used by the patients during study recruitment, were taken into account: corticosteroids, methotrexate, biologics. Russian national vaccine schedule supposes diphtheria-tetanuspertussis vaccination in 3, 41/2, 6 and 18 months and further diphtheria-tetanus vaccination in 6-7 and 14 years and MMR vaccine at the age of 1 year and six years, and hepatitis $B$ vaccination in 0, 1, 6 months. Depending on the number of scheduled vaccines for subsequent analysis, patients цyre divided into two groups with complete and incomplete vaccination. According to the national vaccine schedule, incomplete vaccination means fewer vaccines or vaccine doses to age.

\section{Statistical analysis}

Statistical analysis was performed with the software STATISTICA, version 10.0 (StatSoft Inc., USA) and MedCalc (MedCalc Software, Belgium). Description of quantitative variables was done with median and percentiles $(25 ; 75)$ for continuous variables and in terms of absolute frequencies and percentages for categorical variables. For comparison, the categorical variables Pearson's $\chi 2$ test or the Fisher's exact test in case of expected frequencies $<5$ was used, and comparison of two quantitative variables was carried out using the Mann-Whitney test.

Survival analysis in each group, with a non-protective level of antibodies against vaccine as the event of interest, was conducted using the Kaplan-Meier method. The log-rank test compared survival curves. Factors significantly associated with a time when the non-protective level was detected or not then tested in a Cox proportional hazards regression model, calculating the Hazard-ratio (HR). P-value $<0.05$ was considered as statistically significant.

\section{Results}

\section{Demographics and vaccine coverage}

The characteristics of patients with JIA included in the study presented in Table 1. We included patients with different ages and JIA categories to evaluate the vaccine coverage. The distribution in the JIA categories was similar to a common population. High proportion of children received corticosteroids (25\%) and near the half received biologics: etanercept $-44 \%$, adalimumab $-29 \%$, tocilizumab $-20 \%$ and abatacept $-7 \%$. Sixteen children (9.4\%) received more than one biologic, consequently. 
Table 1

Demographic characteristics of patients with JIA.

\begin{tabular}{|ll|}
\hline Parameter & Results $(\mathbf{n}=\mathbf{1 7 0})$ \\
\hline Girls, $\mathrm{n}(\%)$ & $115(67.7)$ \\
\hline Onset age, years & $6.0(3.7 ; 9.0)$ \\
\hline Study inclusion age, years & $11.4(7.6 ; 14.8)$ \\
\hline JIA duration, years & $3.8(1.9 ; 6.5)$ \\
\hline JIA categories, $\mathrm{n}(\%):$ & \\
\hline Oligoarthritis & $73(42.9)$ \\
Polyarthritis & $61(35.9)$ \\
Systemic arthritis & $16(9.4)$ \\
Enthesitis-related arthritis & $20(11.8)$ \\
\hline Treatment, $\mathrm{n}(\%)$ & \\
\hline Corticosteroids, $\mathrm{n}(\%)$ & $43(25.3)$ \\
Methotrexate, $\mathrm{n}(\%)$ & $154(90.6)$ \\
Methotrexate duration, years. & $2.5(1.1 ; 5.3)$ \\
Biologics, $\mathrm{n}(\%)$ & $82(48.2)$ \\
Biologic duration, years & $1.3(0.1 ; 4.2)$ \\
\hline
\end{tabular}

\section{Incomplete vaccination}

The majority of patients had a restricted number of vaccines which can explain a relatively h proportion of the JIA patients without non-protective levels of antibodies against vaccines. Data are in Table 2. Protective level of antibodies in the whole studied population of JIA patients ranged from $50 \%$ (against hepatitis B) to $98.2 \%$ (rubella). An incomplete complex of vaccines against MMR had 50 (42\%) patients with JIA, against diphtheria 85 (50\%) patients with JIA. All patients received a whole complex of vaccines against hepatitis $\mathrm{B}$. The time between last vaccination and study recruitment is relatively big and ranged from 6.0 years for diphtheria to 10.9 years for hepatitis B. MMR vaccine coverage was similar between oligoarthritis (70\%), polyarthritis (69\%) and systemic arthritis (63\%) except enthesitis-related arthritis (85\%), who were elder and received more vaccine doses before the onset of the disease. The vaccination coverage pattern against diphtheria showed similar results between JIA categories and were $51 \%, 46 \%, 63 \%$ and $50 \%$, relatively. 
Table 2

Vaccine coverage in JIA children.

\begin{tabular}{|ll|}
\hline Parameter & Results, $\mathbf{n}=\mathbf{1 7 0 ,} \mathbf{n}(\%)$ \\
\hline Measles-Mumps-Rubella vaccination & $170(100.0)$ \\
One vaccine & $95(55.9)$ \\
Two vaccines & $50(42.0)$ \\
\hline MMR incomplete vaccination for age, $\mathrm{n}(\%)$ & $7.3(5.0 ; 10.3)$ \\
\hline Time since last MMR vaccination, years (Me; 25\%;75\%) & $82(48.3)$ \\
\hline Diphtheria vaccination & $88(51.7)$ \\
\hline 1-4 vaccines & $85(50)$ \\
\hline 5-6 vaccines & $6.0(4.1 ; 9.6)$ \\
\hline Diphtheria incomplete vaccination for age, $\mathrm{n}(\%)$ & $170(100.0)$ \\
\hline Time since last diphtheria vaccination, years, Me $(25 \% ; 75 \%)$ & $10.9(7.1 ; 14.3)$ \\
\hline Hepatitis B vaccination & $98(57.7)$ \\
\hline Time since last hepatitis B vaccination, years, Me $(25 \% ; 75 \%)$ & $136(80,0)$ \\
\hline Patients with anti-measles protective IgG level, $\mathrm{n}(\%)$ & $88(51,8)$ \\
\hline Patients with anti-mumps protective IgG level, $\mathrm{n}(\%)$ & $85(50,0)$ \\
\hline Patients with anti-diphtheria protective lgG level, $\mathrm{n}(\%)$ & $168(98.2)$ \\
\hline Patients with anti-hepatitis B protective IgG level, $\mathrm{n}(\%)$ & \\
\hline Patients with anti-rubella protective IgG level, $\mathrm{n}(\%)$ & \\
\hline
\end{tabular}

Comparing children with complete and incomplete vaccination showed the lower levels of antibodies against mumps and diphtheria and the number of patients with protective levels of antibodies against diphtheria were found in patients with incomplete vaccination. Incomplete vaccination was associated with lower levels of antibodies against parotitis and diphtheria (Table 3). 
Table 3

Levels of antibodies against vaccines in JIA patients depend on vaccine coverage

\begin{tabular}{|c|c|c|c|}
\hline \multirow[t]{2}{*}{ Parameters } & \multicolumn{2}{|l|}{ MMR vaccination } & \multirow[t]{2}{*}{ p } \\
\hline & Incomplete $(n=50)$ & Complete $(n=120)$ & \\
\hline Anti-measels lgG, Me/ml & $0.2(0.0 ; 0.5)$ & $0.2(0.09 ; 0.6)$ & 0.181 \\
\hline Patients with anti-measles protective IgG level, $\mathrm{n}(\%)$ & $25(50)$ & $73(60.8)$ & 0.193 \\
\hline Anti-mumps lgG, $\mathrm{Me} / \mathrm{ml}$ & $1.9(0.0 ; 5.1)$ & $2.9(1.3 ; 5.3)$ & 0.101 \\
\hline Patients with anti-mumps protective IgG level & $35(70.0)$ & $101(84.2)$ & 0.035 \\
\hline Anti-rubella lgG, Me/ml & $69.9(36.9 ; 119.6)$ & $87.3(45.3 ; 198.3)$ & 0.173 \\
\hline Patients with anti-rubella protective IgG level, $\mathrm{n}(\%)$ & $49(98.0)$ & $119(99.2)$ & 0.520 \\
\hline \multirow[t]{3}{*}{ Time since the last MMR vaccination, years } & $5.5(4.0 ; 7.5)$ & $7.6(4.9 ; 10.6)$ & 0.156 \\
\hline & \multicolumn{2}{|c|}{ Diphtheria vaccination } & \\
\hline & Incomplete $(\mathrm{n}=85)$ & Complete $(\mathrm{n}=85)$ & \\
\hline Anti-diphtheria lgG, Me/ml & $0.07(0.03 ; 0.22)$ & $0.2(0.06 ; 0.4)$ & 0.001 \\
\hline Patients with anti-diphtheria protective lgG level, $\mathrm{n}(\%)$ & $34(40.0)$ & $54(63.5)$ & 0.002 \\
\hline Time since last diphtheria vaccination, years & $5.4(4.1 ; 9.0)$ & $6.1(4.8 ; 9.3)$ & 0.468 \\
\hline
\end{tabular}

Incomplete vaccination is a risk factor of non-protective level of antibodies against measles $(\mathrm{HR}=2.03$ [95\% Cl:1.02; 4.0], $\mathrm{p}=$ 0.042), parotitis $(\mathrm{HR}=6.25[95 \% \mathrm{Cl}: 2.13 ; 17.9], \mathrm{p}=0.0008)$ and diphtheria $(\mathrm{HR}=2.39[95 \% \mathrm{Cl}: 1.18 ; 4.85], \mathrm{p}=0.016)$ vaccines, which was confirmed with Cox proportional regress models (Fig. 1).

Incomplete vaccination was strongly associated with the severity of arthritis and the degree of immunosuppression. Incomplete MMR vaccination had $39 \%$ of patients, treated with biologics, $22 \%$ with MTX and $14 \%$ with NSAID. A similar pattern was observed in diphtheria vaccination: $61 \%, 46 \%$ and $36 \%$ respectively in distinct treatment groups.

\section{Risk factors of non-protective levels of antibodies against vaccines}

The possible factors might influence the level of antibodies against vaccine were JIA category, treatment modalities, vaccine coverage, and time since last vaccination, so best options were time-dependent statistical methods. In survival analysis, we have found differences in patients with protective and non-protective levels of antibodies only against hepatitis B (LogRank test, $p=0,018$ ). The lowest probability of having a protective level of antibodies was observed in systemic arthritis compared to oligoarthritis $(p=0.008)$ and polyarthritis $(p=0.005)$.

JIA patients, with non-protective levels of antibodies against measles, had more extended methotrexate treatment (2.8 [1.3; $6.4]$ vs $2.2[0.9 ; 3.9]$ years, $p<0.05)$ and increased applying of the biologics $(76 \%$ vs $52 \%, p<0.05)$ compare to the patients with protective levels of antibodies. Patients treated with biologics had the lowest probability of having protective levels of antibodies against measles, mumps, hepatitis B, and diphtheria than MTX and NSAID (Fig. 2).

Patients with non-protective antibodies against mumps had lower vaccine coverage $(56 \%$ vs $67 \%, p<0.05)$. Patients with nonprotective levels of antibodies against diphtheria had lower vaccine coverage too $(38 \%$ vs $61 \%, p<0.01)$, longer duration of methotrexate $3.3[1.4 ; 6.7]$ vs $1.8[1.0 ; 2.9]$ years, $p<0.01)$ and biologic treatment $3.1[1.1 ; 5.4]$ vs $0.9[0.0 ; 1.9]$ years, $p<0.05)$ compare to patients with protective levels. The main risk factors to have non-protective levels of antibodies against specific vaccines are in Table 4. 
Table 4

Risk factors, associated with non-protective levels of antibodies against measles, parotitis, rubella, diphtheria and hepatitis B vaccines (proportional hazard Cox regression models).

\begin{tabular}{|c|c|c|c|c|c|c|c|c|c|c|}
\hline \multirow[t]{2}{*}{ Parameters } & \multicolumn{2}{|l|}{ Measles } & \multicolumn{2}{|l|}{ Parotitis } & \multicolumn{2}{|l|}{ Rubella } & \multicolumn{2}{|l|}{ Diphtheria } & \multicolumn{2}{|c|}{ Hepatitis B } \\
\hline & $\begin{array}{l}\mathrm{HR} \\
(95 \% \mathrm{Cl})\end{array}$ & $p$ & $\begin{array}{l}\mathrm{HR} \\
(95 \% \mathrm{Cl})\end{array}$ & $\mathrm{p}$ & $\begin{array}{l}\mathrm{HR} \\
(95 \% \mathrm{Cl})\end{array}$ & $p$ & $\begin{array}{l}\mathrm{HR} \\
(95 \% \mathrm{Cl})\end{array}$ & $p$ & $\begin{array}{l}\mathrm{HR} \\
(95 \% \mathrm{Cl})\end{array}$ & $p$ \\
\hline soJIA, yes & $\begin{array}{l}1.84 \\
(0.84 \\
4.03)\end{array}$ & 0.128 & $\begin{array}{l}1.43(0.53 \\
3.95)\end{array}$ & 0.492 & $\begin{array}{l}0.99 \\
(0.05 \\
18.6)\end{array}$ & 0.995 & $\begin{array}{l}2.04 \\
(0.91 ; 4.59)\end{array}$ & 0.08 & $\begin{array}{l}2.52 \\
(1.27 \\
5.0)\end{array}$ & 0.008 \\
\hline GCS, yes & $\begin{array}{l}1.54 \\
(0.91 \\
2.61)\end{array}$ & 0.104 & $\begin{array}{l}0.31 \\
(0.45 ; 1.84)\end{array}$ & 0.799 & $\begin{array}{l}0.736 \\
(0.11 ; \\
4.88)\end{array}$ & 0.736 & $\begin{array}{l}1.89 \\
3.24)\end{array}$ & 0.02 & $\begin{array}{l}1.34 \\
(0.77 \\
2.32)\end{array}$ & 0.295 \\
\hline MTX, yes & $\begin{array}{l}0.86 \\
(0.39 \\
1.88)\end{array}$ & 0.703 & $\begin{array}{l}1.55(0.49 \\
4.88)\end{array}$ & 0.453 & $\begin{array}{l}1.53 \\
(0.08 \\
28.64)\end{array}$ & 0.776 & $\begin{array}{l}2.02(0.71 ; \\
5.76)\end{array}$ & 0.187 & $\begin{array}{l}0.6 \\
(0.31 \\
1.15)\end{array}$ & 0.122 \\
\hline $\begin{array}{l}\text { Biologics, } \\
\text { yes }\end{array}$ & $\begin{array}{l}2.02 \\
(1.22 \\
3.32)\end{array}$ & 0.006 & $\begin{array}{l}1.76(0.98 \\
3.15)\end{array}$ & 0.057 & $\begin{array}{l}2.26 \\
(0.5 ; \\
9.87)\end{array}$ & 0.293 & $\begin{array}{l}1.67(0.99 \\
2.8)\end{array}$ & 0.053 & $\begin{array}{l}1.2 \\
(0.75 \\
1.92)\end{array}$ & 0.453 \\
\hline $\begin{array}{l}>1 \\
\text { biologics, } \\
\text { consequent, } \\
\text { yes }\end{array}$ & $\begin{array}{l}1.57 \\
(1.13 \\
2.2)\end{array}$ & 0.007 & $\begin{array}{l}1.4(0.93 \\
2.09)\end{array}$ & 0.104 & $\begin{array}{l}1.82 \\
(0.71 \\
4.7)\end{array}$ & 0.213 & $\begin{array}{l}1.4(0.98 \\
2.0)\end{array}$ & 0.062 & $\begin{array}{l}1.11 \\
(0.78 \\
1.58)\end{array}$ & 0.572 \\
\hline $\begin{array}{l}\text { Incomplete } \\
\text { vaccination, } \\
\text { yes }\end{array}$ & $\begin{array}{l}2.02 \\
(1.02 \\
4.0)\end{array}$ & 0.042 & $\begin{array}{l}6.25(2.13 \\
17.9)\end{array}$ & 0.00008 & na* & na* & $\begin{array}{l}2.39 \\
4.85)\end{array}$ & 0.016 & na* & na* \\
\hline
\end{tabular}

\section{Discussion}

Our study aimed to describe vaccine coverage status and vaccine immunity status in JIA patients in a Russian tertiary centre. The launch of vaccination drastically decreased the incidence of infections around the world and prevented many deaths [18]. The European League Against Rheumatism recommended the national guidelines for the vaccination of PRD [19]. High vaccine coverage in the population may prevent blocking infection in the circulation. It is necessary to have a very high proportion of the people with protective antibodies level. The population threshold level required for blocking the virus's circulation is $95 \%$ for measles, $90 \%$ for mumps and $85 \%$ for rubella [20].

\section{Vaccine Immunity Against Mmr}

In the large epidemiological study in Netherland in $400 \mathrm{JIA}$ patients the lower level of antibodies against mumps $(\mathrm{OR}=0.4$; $95 \% \mathrm{Cl} 0.3$ to 0.6$)$ and rubella (OR $=0.4 ; 95 \mathrm{Cl}$ : 0.3 to 0.7$)$ were detected, but not against measles $(\mathrm{OR}=1.4 ; 95 \% \mathrm{Cl}: 0.8$ to 2.5$)$ compare to 2176 healthy controls [21]. Lower levels of antibodies against measles $(p=0.025)$, mumps $(p=0.018)$ and rubella $(p=0.077)$ were detected in systemic JIA. Seroprotection rate among JIA patients was $93.9 \%$ for measles, $85.1 \%$ for mumps and 89.8 for rubella, compared to healthy controls: $87.4 \%, 85.0 \%$ and $90.3 \%$, consequently. Glucocorticoids and methotrexate did not significantly affect the antibodies levels. In our study, only $57.7 \%$ of JIA patients had protective antibodies against measles, which is lower than epidemiological data and previously published data. According to the official statistics in SaintPetersburg the $97.4-99.6 \%$ of the population of different ages has received the MMR vaccination, but the number of people without protective antibodies in 2019 is higher and ranged from 6.3 to $17.9 \%$ in children and $5-27.1 \%$ in adults (18-49 years) 
[22]. In our study, incomplete vaccination and treatment with biologic affect the antibodies' level against measles (Fig. 1, 2, Table 4). The seroprotection level against mumps was relatively high, at $80 \%$, but lower than local epidemiological data [22]. Incomplete vaccination and biologics were the main predictors of anti-mumps antibodies' non-protective level, similar to measles (Fig. 1, 2, Table 4).

The situation with rubella is much better as well in our cohort, as in the population. The number of seronegative subjects in Saint-Petersburg population in 2019 ranged from 2.1 to 4.8 in children and 3.0-8.2 in adults (18-49 years) [22]. In our cohort, $98.2 \%$ of JIA patients had a protective level of antibodies despite the number of vaccines and was similar to population and previous studies. High protective levels of antibodies against rubella could be measured during 20 years even after one vaccine dose $[23,24]$. Our study had no chances to find the risk factors of impaired anti-rubella immunity due to the small sample size of patients with non-protective levels of antibodies. Vaccination against MMR was safe and effective according to the previous studies [25-27].

\section{Vaccine Immunity Against Diphtheria}

In 29 patients (2-5 years) with polyarticular JIA who received subcutaneous abatacept the protective levels of antibodies against diphtheria were detected in 26 (89.7\%). Methotrexate and low-dose of corticosteroids do not affect the antibodies level, 19/20 (95\%) who received methotrexate or methotrexate with a low dose of corticosteroids compare to $7 / 9$ (77.8\%) of patients receiving no corticosteroids or methotrexate [28]. Protective level of antibodies against diphtheria was detected in $51.8 \%$ of our JIA patients which was lower than local population data. In the study of Brunner $\mathrm{H}$, et al. in children of 25 years the protective level was similar $-91 / 102(89.2 \%)$ and also did not depend on methotrexate with and without low dose corticosteroids ( $75 \%$ vs $66.7 \%, p=0.756)$, and biologics $(66.7 \%$ vs $69.2, p=0.931)$. According to the CDC, complete vaccination provides a protective level in $95 \%$ of healthy children [29]. In Saint-Petersburg in 2019, the protective antibodies against diphtheria had $96.9 \%$ of healthy children and $94.1-94.9 \%$ of adults, according to the official data similar to CDC data. In $400 \mathrm{JIA}$ patients, the level of antibodies against diphtheria (OR $0.1 ; 0.06$ to 0.2 ) and tetanus (OR $0.1 ; 0.05$ to 0.3$)$ were lower in JIA patients compare to 2176 healthy controls [21]. Methotrexate and corticosteroids did not significantly influence the geometric median antibody concentration, except for the weak negative correlation between methotrexate usage and the antibody levels against diphtheria $(r=-0.28)$. In our study, incomplete vaccination, duration of methotrexate and biologics, affected the level of antibodies against diphtheria. No differences in the seroprotection rates for diphtheria were observed between JIA categories in our study and previous [21].

\section{Vaccine Immunity Against Hepatitis B}

The vaccine against hepatitis $B(\mathrm{HB})$ is recombinant and may be recommended for vaccination to all immune-compromised children because of safety and efficacy [30-32]. Japanese College of Rheumatology and the Japanese College of Hepatology considered anti-HB vaccination for unimmunized patients with JIA as soon as JIA has been under control for three months $[31,32]$. The protective level of anti-HBs antibodies had $50 \%$ of our studied JIA group, and all patients had complete vaccination due to the earliest course (before six months). In the Polish study, $60.7 \%$ of JIA patients with similar ages had protective levels of antibodies against hepatitis B. Girls, and patients with polyarticular JIA had the lowest levels of antibodies [33]. Only half of the patients with different PRD receiving immunosuppressive treatment had a protective anti-HBs level compare to controls - 4\% [33]. In Maritsi D. et al. in 89 patients with a different JIA form, only 55\% had a protective level of anti-HBs antibodies and $92 \%$ in healthy controls [34]. According to the literature data, the vaccination of JIA patients against $\mathrm{HB}$ is safe and effective [30,31]. Kasapcopur et al. showed that the level of seroprotection was achieved by $38 / 39(98 \%)$ in patients with different forms of JIA treated with methotrexate or methotrexate with prednisolone. No vaccine-associated reaction or disease flares occurred [30]. In the study of $18 \mathrm{JIA}$ children without a history of anti-HB vaccination treated with different biologic drugs, in 13, the protective level confirmed. Patients received 0, 1, 6 months scheduled vaccination, and the adverse reaction was in 5 patients who were similar to healthy children. No JIA flares observed in the studied group [31]. In our 
group, the main predictors affecting antibodies against hepatitis B were a systemic-onset category of JIA and biologics treatment.

Several issues in the vaccination process and maintenance of anti-vaccine antibodies have identified. Many patients (near $40 \%$ ) who developed arthritis early (before 6-7 years) often miss the following scheduled vaccinations, e.g. measles, mumps, diphtheria, tetanus [35]. Usually, most patients with oligoarthritis and half of the RF-negative polyarthritis patients are in the risk of incomplete vaccination [36]. Incomplete vaccination is a usual problem for JIA and other PRD patients. Incomplete vaccination against MMR had $42 \%$ and against diphtheria $50 \%$ of our patients. In Slovenian study, $35 \%$ of 187 PRD children had incomplete vaccination. The mostly omitted vaccines were hepatitis B and the second dose of MMR similar to our group [37]. In Canadian study with $200 \mathrm{JIA}$ children, the incomplete vaccination had $48 \%, 32 \%$, and $39 \%$ of patients at 2.5 years, 10.5 years and their last clinic visit, respectively [38]. In 715 JIA children from Germany, incomplete vaccination status had one-third of patients. The main reason for incomplete vaccination was physicians' suggestion. The vaccination coverage in preschool children was similar to healthy matches and lower in adolescents (24-79\% for diphtheria and tetanus and $60-75 \%$ for MMR) with JIA. More incomplete vaccination cases were among polyarticular and systemic JIA patients than oligoarticular and who received immunosuppressive therapy compared to children without immunosuppression [39]. Our results are similar. Minimal vaccine coverage has been observed in patients with immunosuppression therapy (biologics, methotrexate) compared to patients with NSAID alone (Table 4).

Interestingly, incomplete vaccination affects predominantly anti-measles, anti-mumps, and anti-diphtheria antibodies maintenance without significant influence on other vaccine-specific antibodies. In our cohort, the main reasons for interrupted or omitted vaccination were parental fear of JIA flare. Similar professional behaviour of Russian healthcare providers was observed too, as in Canada and in Brazil, where $38 \%$ of 82 and $43.5 \%$ of 207 PRD consequently have omitted the vaccination due to fear of parents or the recommendation of the physicians $[40,41]$. There are many concerns from patients, their parents, and healthcare providers about vaccination safety in immunocompromised children, e.g. JIA [13, 15; 42]. Many physicians had concerns and uncertainty about the role of vaccines in the JIA flares, which realized in the interruption or discordance in the vaccine practice. Physicians make some delays in the scheduled vaccination before a certain period (e.g., stabilizing the disease or more prolonged remission) or neglecting some vaccine $[13,42]$. Our primary care physicians and some pediatric rheumatologists, unfortunately, acted in the same way.

The main risks of incomplete vaccination related to JIA's onset age and parents or healthcare providers have started to omit vaccination. In our study, patients with onset age less than four years had a risk of incomplete vaccination of MMR $(O R=12.2$ $(5.0 ; 29.9), p=0.0000001)$ and diphtheria $(O R=1.9(0.9 ; 3.8), p=0.08)$. Younger onset age led to an interruption of vaccination because of abovementioned reasons. Similar to onset age, duration of JIA $>3$ years was a risk factor of incomplete vaccination of MMR $(\mathrm{OR}=4.4 ;(2.0 ; 9.9)$ and diphtheria $(\mathrm{OR}=3.4 ;(1.8 ; 6.5), \mathrm{p}=0.0002)$, as well as biologic treatment for $\mathrm{MMR}$ $(\mathrm{OR}=2.5(1.3 ; 4.9), \mathrm{p}=0.008)$ and diphtheria $(\mathrm{OR}=2.4(1.3 ; 4.4), \mathrm{p}=0.006)$. Usually, vaccine coverage is correlated with the patient's age. Elder children have more omitted vaccines [37]. According to the patient's age, our patients did not show significant differences in vaccine coverage: $65 \%-65 \%-80 \%$ for MMR and $45 \%-46.7 \%-54.6 \%$ for diphtheria in patients with age grades $2-7$ years, $8-12$ years and $13-17$ years, consequently.

The second issue is related to anti-rheumatic drugs' effect on the immune system functioning, especially B-cells and memory B-cells. Children with PRD may have reduced levels of anti-vaccine antibodies against measles, mumps, rubella, diphtheria, tetanus and hepatitis B compared to age-matched healthy controls [21,34]. Children with PRD may have lower levels of antivaccine antibodies if they have not even received any medications [43]. Several studies in PRD patients showed a similar response to healthy controls, but sometimes the antibody levels might be lower. Disease activity usually does not affect the antibody generation and maintenance if vaccinated patients were not in the remission [44-45].

The main unresolved question is related to the different ability of anti-rheumatic medications affects the levels of antibodies against the vaccine. In previous studies, methotrexate and corticosteroids' negative effect on the antibodies against measles, 
mumps, rubella, diphtheria, and tetanus was not shown $[21,27,28,46,47]$. However, other studies have shown the opposite data $[31,33,48]$.

Revaccination of JIA patients is effective and safe and should be encouraged, especially in patients with incomplete vaccination or low anti-vaccine antibody levels. In the randomized study, the antibody against measles was higher in the JIA patients, who received revaccination compare to control group (JIA patients have not received revaccination). No cases of measles, mumps and rubella were detected after the vaccination [26]. According to the EULAR recommendations-2011 inactivated vaccines are safe, independently to a type of treatment and live attenuated vaccines should be used individually on the case-to-case basis, regarding disease activity, treatment modalities and the risk-benefit ratio. However, more precise recommendations and guidelines are required [19].

In real practice, the situation with the vaccination of immunocompromised children looks safe and effective. No increased flare rate was shown in JIA patients during the vaccination in several studies. In Australia, the flare rate during 90-days after vaccination was lower than patients' baseline risk $(R R=0.59(95 \% \mathrm{Cl} 0.39-0.89, p=0.012)$. Authors explained the reduced risk that "children may be healthier than usual' by the time of vaccination, a vaccine was delayed before the time "free of viral infection" and so on [50]. In the literature, there are at least 29 studies about vaccination of JIA patients. Among them were different types of articles, ranged from case reports to randomized trials. In all studied vaccines against influenza, MMR, varicella, pneumococcus, human papillomavirus and hepatitis B in JIA patients no increased flared risk, related to vaccination was identified [25, 49-50].

In our study, the main predictors affected the anti-vaccine antibody levels were incomplete vaccination, JIA category, duration of methotrexate treatment and biologics. Corticosteroids did not affect the antibodies levels, except the anti-diphtheria antibodies, possibly due to using them in a short-term manner, as the bridge therapy. According to EULAR recommendation and published data about vaccine status we can strongly recommend routinely check patient's vaccine schedule and in patients with incomplete vaccination and patients having a risk of non-protective levels of antibodies should routinely check the anti-vaccine antibody levels and encourage patients and their families to continue vaccination with individual vaccination program [19]. It is necessary to provide simple algorithms for primary care physicians about the management of vaccinations, routine antibodies checking. The vaccine coverage in our population is non-optimal compare to other countries and our healthy population. Interdisciplinary communication between rheumatologist, immunologist, primary care physicians and healthcare providers is still required to improve vaccine coverage in JIA patients.

\section{Limitations Of The Study}

The present study's main limitations are related to JIA patients' differences in age, JIA categories, treatment approaches, and the time gap between last vaccination and study recruitment. The different onset age and duration of the disease before the obtaining samples are the additional factors that influence anti-vaccine antibodies' survival to diseases pathogenesis and treatment.

\section{Conclusion}

Children with JIA have lower antibody levels, and many JIA patients have non-protective levels of antibodies against vaccines and require a routine check. Incomplete vaccination, JIA category, biologics, corticosteroids, and long-term methotrexate treatment might be supposed to be the risk factors of aberrant vaccine immunity. Individual vaccination schedule required for JIA patients without protective antibody levels and should be tailored by individual basis with antibody levels sampling. It is necessary to decrease the level of parental fair and healthcare providers against vaccination in Russia. Further studies about the safety and efficacy of vaccination in JIA patients required.

\section{Abbreviations}


$\mathrm{Cl}$ - confidence interval; EULAR - European League Against Rheumatism; HB - hepatitis B; HR - hazard ratio; JIA - juvenile idiopathic arthritis; MMR - measles, mumps, rubella; OR - odds ratio; PRD - pediatric rheumatic disease; RR - relative risk; TNF- a - tumour necrosis factor inhibitor.

\section{Declarations}

Ethics: Written consent has obtained according to the declaration of Helsinki. The Saint Petersburg State Pediatric Medical University's local Ethics Committee approved the trial protocol (protocol number 9/2 from 02.09.2019).

Consent for publication: All authors are agree to publish the manuscript

Availability of data and material: The datasets used and/or analysed during the current study are available from the corresponding author on reasonable request.

Competing interests. The authors declare that they have no competing interests

Funding statement: This work was financially supported by the Ministry of Science and Higher Education of the Russian Federation (Agreement No. 075-15-2020-901)

\section{Authors' contributions:}

M. M. Kostik: Substantial contributions to the conception or design of the work; or the acquisition, analysis, or interpretation of data for the work; drafting the work or revising it critically for important intellectual content; final approval of the version to be published; Agreement to be accountable for all aspects of the work in ensuring that questions related to the accuracy or integrity of any part of the work are appropriately investigated and resolved. ORCID: (0000-0002-1180-8086), e-mail: kostmikhail@yandex.ru; mikhail.kostik@gmail.com

N. A. Lubimova: Substantial contributions to the conception or design of the work; or the acquisition, analysis, or interpretation of data for the work; drafting the work or revising it critically for important intellectual content; final approval of the version to be published; Agreement to be accountable for all aspects of the work in ensuring that questions related to the accuracy or integrity of any part of the work are appropriately investigated and resolved. ORCID: (0000-0002-3187-8997), e-mail: natali18111989@gmail.com

I.V. Fridman: Substantial contributions to the conception or design of the work; or the acquisition, analysis, or interpretation of data for the work; drafting the work or revising it critically for important intellectual content; final approval of the version to be published; Agreement to be accountable for all aspects of the work in ensuring that questions related to the accuracy or integrity of any part of the work are appropriately investigated and resolved. ORCID: (0000-0002-2633-491X) e-mail: fridiv@mail.ru

Olga V. Goleva: Substantial contributions to the conception or design of the work; or the acquisition, analysis, or interpretation of data for the work; drafting the work or revising it critically for important intellectual content; final approval of the version to be published; Agreement to be accountable for all aspects of the work in ensuring that questions related to the accuracy or integrity of any part of the work are appropriately investigated and resolved. ORCID: (0000-0003-3285-9699) e-mail: golev.ao@mail.ru

S. M. Kharit: Substantial contributions to the conception or design of the work; or the acquisition, analysis, or interpretation of data for the work; drafting the work or revising it critically for important intellectual content; final approval of the version to be published; Agreement to be accountable for all aspects of the work in ensuring that questions related to the accuracy or integrity of any part of the work are appropriately investigated and resolved. ORCID: (0000-0002-2371-2460), e-mail: kharits@mail.ruAll authors read and approved the final manuscript. 
Author contributions: All authors were involved in drafting the article or revising it critically. All authors approved the final version to be submitted for publication. Dr. Kostik, Dr. Lubimova, and Dr. Kharit had full access to all of the data in the study and took responsibility for the data integrity and the accuracy of the data analysis.

Study conception and design: Kostik, Kharit

Acquisition of data: Kostik, Lyubimova, Fridman

Analysis and interpretation of data: Kostik, Goleva, Kharit

\section{References}

1. Ravelli A, Martini A. Juvenile idiopathic arthritis. Lancet. 2007;369(9563):767-78. https//doi.org/10.1016/S01406736(07)60363-8.

2. Cassidy JT. Textbook of pediatric rheumatology. 6th ed. Philadelphia: Saunders; 2011.

3. Breda L, Del Torto M, De Sanctis S, Chiarelli F. Biologics in children's autoimmune disorders: efficacy and safety. Eur J Pediatr. 2011;170:15767. https//doi.org/10.1007/s00431-010-1238-z.

4. Atzeni F, Bendtzen K, Bobbio-Pallavicini F, Conti F, Cutolo M, Montecucco C, et al. Infections and treatment of patients with rheumatic diseases. Clin Exp Rheumatol. 2008;26(1 Suppl 48):67-73. PMID: 18570757.

5. Horneff G, De Bock F, Foeldvari I, Girschick HJ, Michels H, Moebius D, et al. Safety and efficacy of combination of etanercept and methotrexate compared to treatment with etanercept only in patients with juvenile idiopathic arthritis (JIA): preliminary data from the German JIA Registry. Ann Rheum Dis. 2009;68(4):519-25. https//doi.org/10.1136/ard.2007.087593.

6. Ruperto N, Lovell DJ, Cuttica R, Wilkinson N, Woo P, Espada G, et al. A randomized, placebo-controlled trial of infliximab plus methotrexate for the treatment of polyarticular-course juvenile rheumatoid arthritis. Arthritis Rheum. 2007;56(9):3096-106. https//doi.org/10.1002/art.22838.

7. Ruperto N, Lovell DJ, Quartier P, Paz E, Rubio-Perez N, Silva CA, et al. Long-term safety and efficacy of abatacept in children with juvenile idiopathic arthritis. Arthritis Rheum. 2010;62(6):1792-802. https//doi.org/10.1002/art.27431.

8. Listing J, Strangfeld A, Kary S, et al. Infections in patients with rheumatoid arthritis treated with biologic agents. Arthritis Rheum. 2005;52:340312. https//doi.org/10.1002/art.21386.

9. Curtis JR, Patkar N, Xie A, Martin C, Allison JJ, Saag M, et al. risk of serious bacterial infections among rheumatoid arthritis patients exposed to tumor necrosis factor alpha antagonists. Arthritis Rheum. 2007;56(4):1125-33.

https//doi.org/10.1002/art.22504.

10. Ada G. Vaccines and vaccination. N Engl J Med. 2001;345(14):1042-53. https//doi.org/10.1056/NEJMra011223. PMID: 11586958.

11. Doran MF, Crowson CS, Pond GR, O'Fallon WM, Gabriel SE. Frequency of infection in patients with rheumatoid arthritis compared with controls: a population-based study. Arthritis Rheum. 2002;46(9):2287-93.

https//doi.org/10.1002/art.10524. PMID: 12355475.

12. Glück T, Kiefmann B, Grohmann M, Falk W, Straub RH, Schölmerich J. Immune status and risk for infection in patients receiving chronic immunosuppressive therapy. J Rheumatol. 2005;32(8):1473-80. PMID: 16078322.

13. Davies K, Woo P. British Paediatric Rheumatology Group. Immunization in rheumatic diseases of childhood: an audit of the clinical practice of British Paediatric Rheumatology Group members and a review of the evidence. Rheumatology (Oxford). 2002 Aug;41(8):937 - 41. https//doi.org/10.1093/rheumatology/41.8.937. PMID: 12154212.

14. Glück T, Müller-Ladner U. Vaccination in patients with chronic rheumatic or autoimmune diseases. Clin Infect Dis. 2008 May 1;46(9):1459-65. https//doi.org/10.1086/587063. PMID: 18419456.

15. Conti F, Rezai S, Valesini G. Vaccination and autoimmune rheumatic diseases. Autoimmun Rev. 2008 Dec;8(2):124-8. https//doi.org/10.1016/j.autrev.2008.07.007. PMID: 18700175. 
16. Morin MP, Quach C, Fortin E, Chédeville G. Vaccination coverage in children with juvenile idiopathic arthritis followed at a paediatric tertiary care centre. Rheumatology (Oxford). 2012;51(11):2046-50.

https//doi.org/10.1093/rheumatology/kes175. PMID: 22864995.

17. Petty RE, Southwood TR, Manners P, Baum J, Glass DN, Goldenberg J, et al.; International League of Associations for Rheumatology. International League of Associations for Rheumatology classification of juvenile idiopathic arthritis: second revision, Edmonton, 2001. J Rheumatol. 2004;31(2):390-2. PMID: 14760812.

18. Crawford NW, Buttery JP. Adverse events following immunizations: fact and fiction. Paediatrics Child Health. 2013;23(3):121-4. https//doi.org/10.1016/j.paed.2012.06.004.

19. Heijstek MW, Ott de Bruin LM, Bijl M, Borrow R, van der Klis F, Koné-Paut I, et al. EULAR recommendations for vaccination in paediatric patients with rheumatic diseases. Ann Rheum Dis. 2011;70(10):1704-12.

https//doi.org/10.1136/ard.2011.150193.

20. Nokes DJ, Anderson RM. Measles, mumps, and rubella vaccine: what coverage to block transmission? Lancet. 1988 Dec 10;2(8624):1374. https//doi.org/10.1016/s0140-6736(88)90920-8. PMID:2904099.

21. Heijstek MW, van Gageldonk PG, Berbers GA, Wulffraat NM. Differences in persistence of measles, mumps, rubella, diphtheria and tetanus antibodies between children with rheumatic disease and healthy controls: a retrospective crosssectional study. Ann Rheum Dis. 2012;71(6):948-54. https//doi.org/10.1136/annrheumdis-2011-200637.

22. http://78.rospotrebnadzor.ru/sanepidobstan.

23. Böttiger M, Forsgren M. Twenty years' experience of rubella vaccination in Sweden: 10 years of selective vaccination (of 12-year-old girls and of women postpartum) and 13 years of a general two-dose vaccination. Vaccine. 1997;15(14):153844. https//doi.org/10.1016/s0264-410x(97)00068-6. PMID: 9330465.

24. O'Shea S, Woodward S, Best JM, Banatvala JE, Holzel H, Dudgeon JA. Rubella vaccination: persistence of antibodies for 10-21 years. Lancet. 1988;2(8616):909. https//doi.org/10.1016/s0140-6736(88)92512-3. PMID: 2902357.

25. Uziel Y, Moshe V, Onozo B, Kulcsár A, Tróbert-Sipos D, Akikusa. JDet al; PReS working party of Vaccination Study Group. Live attenuated MMR/V booster vaccines in children with rheumatic diseases on immunosuppressive therapy are safe: Multicenter, retrospective data collection. Vaccine. 2020 Feb 24;38(9):2198-2201. https//doi.org/10.1016/j.vaccine.2020.01.037. Epub 2020 Jan 24. PMID: 31987692.

26. Heijstek MW, Kamphuis S, Armbrust W, Swart J, Gorter S, de Vries LD, et al. Effects of the live attenuated measles-mumpsrubella booster vaccination on disease activity in patients with juvenile idiopathic arthritis: a randomized trial. JAMA. 2013 Jun 19;309(23):2449-56. https//doi.org/10.1001/jama.2013.6768. PMID: 23780457.

27. Borte M, Borte S, Sack U, Liebert UG. Efficacy of measles, mumps and rubella revaccination in children with juvenile idiopathic arthritis treated with methotrexate and etanercept. Rheumatology. 2009;48(2):144-8.

https//doi.org/10.1093/rheumatology/ken436.

28. Brunner HI, Tzaribachev N, Cornejo GV, Joos R, Gervais E, Cimaz R, et al. maintenance of antibody response to diphtheria/tetanus vaccine in patients aged 2-5 years with polyarticular-course juvenile idiopathic arthritis receiving subcutaneous abatacept. Pediatr Rheumatol Online J. 2020;18(1):19. https//doi.org/10.1186/s12969-020-0410-x.

29. Centers for Disease Control and Prevention. Chapter 21: Tetanus. Epidemiology and Prevention of Vaccine-Preventable Diseases. 2015.

30. Kasapçopur O, Cullu F, Kamburoğlu-Goksel A, Cam H, Akdenizli E, Calýkan S, et al. Hepatitis B vaccination in children with juvenile idiopathic arthritis. Ann Rheum Dis. 2004;63(9):1128-30. https//doi.org/10.1136/ard.2003.013201. PMID: 15308522; PMCID: PMC1755134.

31. Nerome Y, Akaike H, Nonaka Y, Takezaki T, Kubota T, Yamato T, et al. The safety and effectiveness of HBV vaccination in patients with juvenile idiopathic arthritis controlled by treatment. Mod Rheumatol. 2016;26(3):368-71. https//doi.org/10.3109/14397595.2015.1085608.

32. Kobayashi I, Mori M, Yamaguchi K, Ito S, Iwata N, Masunaga K, et al. Pediatric Rheumatology Association of Japan recommendation for vaccination in pediatric rheumatic diseases. Mod Rheumatol. 2015;25(3):335 - 43. https//doi.org/

Page $13 / 16$ 
10.3109/14397595.2014.969916. PMID: 25381726.

33. Szczygielska I, Hernik E, Gazda A, Kołodziejczyk B, Gietka P. Assessment of anti-HBs antibody concentration in children with juvenile idiopathic arthritis treated with biological drugs, vaccinated against viral type B hepatitis in infancy. Reumatologia. 2020;58(1):15-20. https//doi.org/10.5114/reum.2020.93508.

34. Maritsi D, Vartzelis G, Soldatou A, Garoufi A, Spyridis N. Markedly decreased antibody titers against hepatitis B in previously immunized children presenting with juvenile idiopathic arthritis. Clin Exp Rheumatol. 2013;31(6):969-73. PMID: 23806191.

35. Berthold E, Månsson B, Kahn R. Outcome in juvenile idiopathic arthritis: a population-based study from Sweden. Arthritis Res Ther. 2019;21(1):218. https//doi.org/10.1186/s13075-019-1994-8. PMID: 31661011; PMCID: PMC6816211.

36. Sansonetti PJ. Measles 2018: a tale of two anniversaries. EMBO Mol Med. 2018;10(5):e9176. https//doi.org/10.15252/emmm.201809176. PMID: 29685959; PMCID: PMC5938618.

37. Bizjak M, Blazina Š, Zajc Avramovič M, Markelj G, Avčin T, Toplak N. Vaccination coverage in children with rheumatic diseases. Clin Exp Rheumatol. 2020;38(1):164-70. PMID: 31577215.

38. Morin MP, Quach C, Fortin E, Chédeville G. Vaccination coverage in children with juvenile idiopathic arthritis followed at a paediatric tertiary care centre. Rheumatology (Oxford). 2012;51(11):2046-50.

https//doi.org/10.1093/rheumatology/kes175. PMID: 22864995.

39. Minden K, Niewerth M, Borte M, Singendonk W, Haas JP. Immunization in children and adolescents with rheumatic diseases [Impfungen bei rheumatischen Erkrankungen des Kindes- und Jugendalters. Z Rheumatol. 2007;66:111-20.

40. Vazhappilly S, Vanderkooi O, Benseler S, Tommy Gerschman NJ, Nadia Luca et al.: Immunization Status and Barriers in Childhood Rheumatic Diseases (abstract). American College of Rheumatology/ Association of Rheumatology Health Professionals Annual Meeting, 2014.

41. Lima Melo JM, Pileggi GC, Martins De Carvalho L, Leme Ferriani VP: Immunization status of children with rheumatic diseases: can the pediatric rheumatologist help to improve? (abstract) Pediatric Rheumatology European Society Congress, 2010.

42. Silva CAA, Terreri MTRA, Aikawa NE, Jozélio FCarvalholll, Gecilmara CS, PileggilV; Virginia PL, et al. Prática de vacinação em crianças com doenças reumáticas. Revista Brasileira de Rheumatologia. 2010;50(4):351-5. https//doi.org/10.1590/S0482-50042010000400002.

43. Heijstek MW, Scherpenisse M, Groot N, Wulffraat NM, Van Der Klis FR. Immunogenicity of the bivalent human papillomavirus vaccine in adolescents with juvenile systemic lupus erythematosus or juvenile dermatomyositis. J Rheumatol. 2013;40(9):1626-7. https//doi.org/10.3899/jrheum.130246.

44. Kashef S, Ghazizadeh F, Derakhshan A, Farjadian S, Alyasin S. Antigen-specific antibody response in juvenile-onset SLE patients following routine immunization with tetanus toxoid. Iran J Immunol. 2008;5:181-4.

45. Wiesik-Szewczyk E, Romanowska M, Mielnik P, Chwalińska-Sadowska H, Brydak LB, Olesińska M, et al. Anti-influenza vaccination in systemic lupus erythematosus patients: an analysis of specific humoral response and vaccination safety. Clin Rheumatol. 2010;29:605-13. https://doi.org/10.1007/s10067-010-1373-y.

46. Kasapçopur O, Cullu F, Kamburoğlu-Goksel A, Cam H, Akdenizli E, Calýkan S, et al. Hepatitis B vaccination in children with juvenile idiopathic arthritis. Ann Rheum Dis. 2004;63(9):1128-30. https//doi.org/10.1136/ard.2003.013201. PMID: 15308522; PMCID: PMC1755134.

47. Shinoki T, Hara R, Kaneko U, Miyamae T, Imagawa T, Mori M, et al. Safety and response to influenza vaccine in patients with systemic-onset juvenile idiopathic arthritis receiving tocilizumab. Mod Rheumatol. 2012;22(6):871-6. https//doi.org/10.3109/s10165-012-0595-z.

48. Stoof SP, Heijstek MW, Sijssens KM, van der Klis F, Sanders EA, Teunis PF, et al. Kinetics of the long-term antibody response after meningococcal $\mathrm{C}$ vaccination in patients with juvenile idiopathic arthritis: a retrospective cohort study. Ann Rheum Dis. 2014;73(4):728-34. https//doi.org/10.1136/annrheumdis-2012-202561. 
49. Alfayadh NM, Gowdie PJ, Akikusa JD, Easton ML, Buttery JP. Vaccinations Do Not Increase Arthritis Flares in Juvenile Idiopathic Arthritis: A Study of the Relationship between Routine Childhood Vaccinations on the Australian Immunization Schedule and Arthritis Activity in Children with Juvenile Idiopathic Arthritis. Int J Rheumatol. 2020;2020:1078914. https//doi.org/10.1155/2020/1078914.

50. Alexeeva El, Vankova DD, Dvoryakovskaya TM, Isaeva KB, Denisova RV, Mamutova AV, et al. Efficacy of Pneumococcal Polysaccharide Conjugate Vaccine (13-valent, Adsorbed) in Patients with Systemic Juvenile Idiopathic Arthritis Treated with Genetically Engineered Biologic Drugs (Tocilizumab or Canakinumab): Prospective Cohort Study. Voprosy sovremennoi pediatrii -. Current Pediatrics. 2020;19(3):190-9. https//doi.org/10.15690/vsp.v19i3.2114.

\section{Figures}
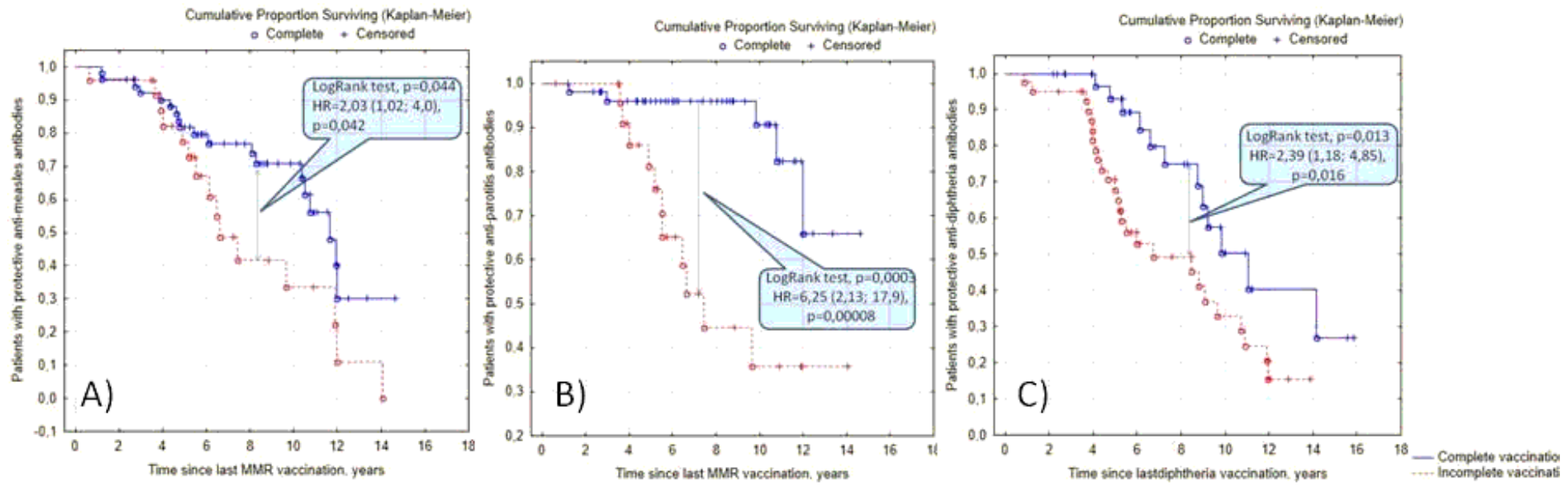

\section{Figure 1}

Incomplete vaccination is a risk factor of non-protective level of antibodies against measles (HR=2.03 [95\%Cl:1.02; 4.0], $\mathrm{p}=0.042)$, parotitis $(\mathrm{HR}=6.25$ [95\% Cl:2.13; 17.9], $\mathrm{p}=0.0008)$ and diphtheria $(\mathrm{HR}=2.39$ [95\%Cl:1.18; 4.85], $\mathrm{p}=0.016)$ vaccines, which was confirmed with Cox proportional regress models 

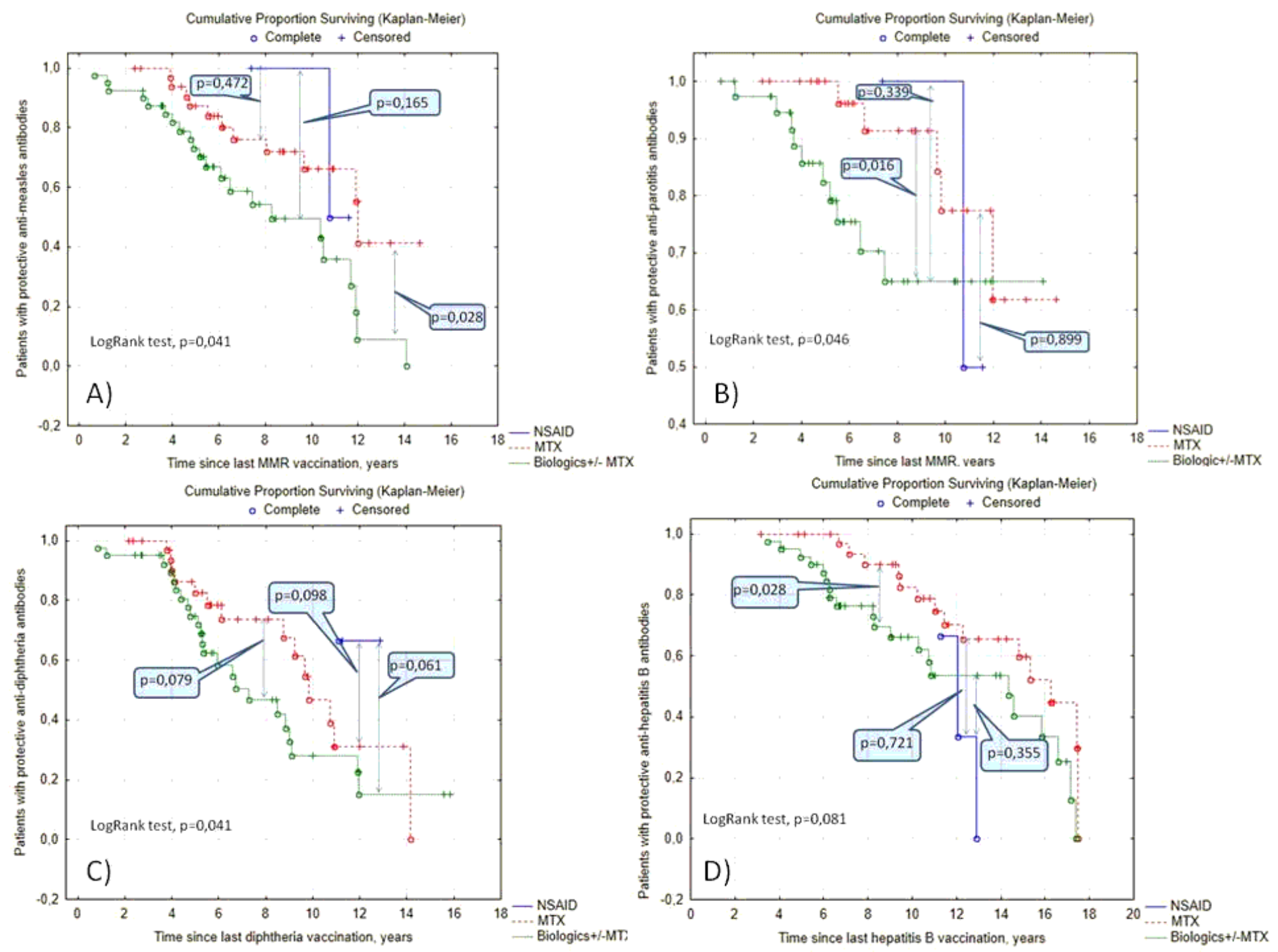

Figure 2

JIA patients, with non-protective levels of antibodies against measles, had more extended methotrexate treatment (2.8 [1.3; $6.4]$ vs $2.2[0.9 ; 3.9]$ years, $p<0.05)$ and increased applying of the biologics $(76 \%$ vs $52 \%, p<0.05)$ compare to the patients with protective levels of antibodies. Patients treated with biologics had the lowest probability of having protective levels of antibodies against measles, mumps, hepatitis B, and diphtheria than MTX and NSAID 